\title{
Components of Host Response to Pathogenic Bacteria in Gingivitis
}

\author{
Jorge Gamonal et al. * \\ Laboratory of Periodontal Biology, Department \\ of Conservative Dentistry, Faculty of \\ Dentistry, University of Chile \\ Chile
}

\section{Introduction}

A classification based on infection as the principal etiology of periodontal diseases divides categories based on gingival inflammation and periodontal attachment loss and recognized health, gingivitis and periodontitis as separate entities (Armitage 1999). Separation of gingivitis from periodontitis suggests that there are differences in these conditions that might include type or severity of infection, and/or adequacy of host response. Data shows that gingivitis in adults can remain stable throughout many years and not endanger the life of the dentition, whereas periodontitis, despite extensive, continues to break down the surrounding hard and soft tissue, leading ultimately to tooth loss (Seymour 1987).

Bacterial biofilms have been shown to be the primary etiological factor in the initiation of gingival inflammation and subsequent destruction of periodontal tissues (Haffaje \& Socransky 1994). Although chronic bacterial and endotoxin exposure is a prerequisite for gingival inflammation and periodontal tissue destruction to occur, its presence alone accounts for a relatively small proportion (i.e. 20\%) of the variance in disease expression and is not enough to explain the (Grossi et al. 1994).

\section{Bacterial specificities}

An attractive hypothesis concerning the role played by Toll Like Receptors (TLRs) in the activation of adaptive immunity holds that the precise combination of TLRs activated by a given microbial infection leads to "tailoring" the adaptive immune response so that it can deal with that specific infection (Hoebe \& Ulevitch 2003). Hence, dendritic cells-stimulated, stimulated by LPS, might direct the development of an adaptive response that is better suited for dealing with Gram-negative organisms than Gram-positive organisms. When the

\footnotetext{
*Nora Silva1,2, Marcela Hernández ${ }^{1,2}$, Nicolás Dutzan"1, Jocelyn Garcia-Sesnich ${ }^{1}$, Loreto Abusleme², Andrea Dezerega ${ }^{1}$ and Rolando Vernal ${ }^{1}$

${ }^{1}$ Laboratory of Periodontal Biology, Department of Conservative Dentistry, Faculty of Dentistry, University of Chile ${ }^{2}$ Pathology Department, Faculty of Dentistry, University of Chile, Santiago, Chile
} 
ability of various oral bacteria to induce innate immune responses from gingival epithelial cells is investigated, the results show that non-periodontopathic and orange-complex bacteria induce weak and strong responses, respectively, but that red-complex bacteria suppress immune responses, live and lysed bacteria showed a difference in their ability to induce immune responses from epithelial cells (Ji et al. 2007). The down-regulation of interleukin-8 by Porphyromonas gingivalis in both mRNA and protein levels, the so-called "chemokine paralysis", has been well characterized (Darveau et al. 1998).

It has been controversial whether oral epithelial cells express TLRs (Asai et al. 2001), in relation to their apparent unresponsiveness to various microbial products in terms of proinflammatory cytokines products. Recently, the authors demonstrated, by immunohistochemical analysis the clear expression of NOD1 and NOD2 in normal oral epithelial tissues, and also showed, using PCR, flow cytometry, and immunostaining, that primary oral epithelial cells in culture expressed these molecules (Sugawara et al. 2006). On the other hand, gingival fibroblasts constitutively expressed proinflammatory cytokines. Upon stimulation, with chemically synthesized ligands mimicking microbial products for the receptors in gingival fibroblast, the production of pro-inflammatory cytokines, such IL-1, IL-6, IL-8 and MCP-1 was markedly up regulated (Uehara et al. 2007). In other study, viable $P$. gingivalis induced a strong in vitro inflammatory response in both gingival and periodontal ligament fibroblasts incremented gene expression of interleukin (IL)-1 $\beta$, IL-6, IL8, TNF- $\alpha$ and secreted RANTES (Scheres et al. 2010). These findings indicate that these innate immunity-related molecules in gingival fibroblasts are functional receptors involved in inflammatory reactions in periodontal tissue, which might be responsible for periodontal pathogenesis.

P. gingivalis, a Gram-negative, anaerobic oral black-pigmented rod, is suspected to be a periodontopathic bacterium and has been frequently isolated from the periodontal pockets of patients with periodontal diseases (Slots \& Listgarten 1988), and the virulence of $P$. gingivalis has been attributed to a variety of factors, including hemagglutinins, cysteine proteinases, and fimbriae (Lamont \& Jenkinson 1998). Although fimbriae function as a colonization factor (Lamont \& Jenkinson 1998), evidence suggests that their virulence role may extend to immunomodulation of the macrophage response to $P$. gingivalis, through coordinated interaction with pattern-recognition receptors (Hajishengallis et al. 2006). Recently, a study demonstrated that $P$. gingivalis expressing wild-type fimbriae may exploit the TLR2/complement receptor 3 pathway for intracellular entry, and persisting in macrophages and by reducing the production of IL-12p70, which may facilitate the survival of other microbes that cohabit its niche in the oral biofilm (Wang et al. 2007). These results support the concept that pathogens evolved to manipulate innate immunity for promoting their adaptive fitness and, consequently, their capacity to cause disease (Finlay \& McFadden 2006). The chemical and biological properties of $P$. gingivalis LPS and its lipid A are different from those of enterobacterial LPS and their lipid A (Ogawa 1994), and different forms of $P$. gingivalis lipid functionally interact with only TLR4 (Sawada et al. 2007). Milward et al. (Milward et al. 2007) demonstrated that Fusobacterium nucleatum and Porphyromonas gingivalis have differential effects at the molecular level on oral epithelial cells and that their differences in activating NF- $\mathrm{KB}$ nuclear translocation in oral epithelial cells may at least in part be responsible for the change in dynamics and kinetics of downstream gene expression. Genes encoding for structural components of the cytoskeleton, namely cytokeratins, were 
detected as being differentially expressed in oral epithelial cells in response to challenge by Fusobacterium nucleatum and Porphyromonas gingivalis. It is therefore conceivable that bacteria may stimulate alterations in cytokeratin expression to gain entry into the underlying gingival tissues.

Challenge of human gingival epithelial cells with Aggregatibacter (Actinobacillus) actinomycetemcomitans has been shown to induce the secretion of several pro-inflammatory cytokines (Dongari-Bagtzoglou \& Ebersole). A previous focus in research on $A$. actinomycetemcomitans leukotoxin has been on its ability to kill neutrophils, the primary defense line against bacteria in the periodontal pocket (Johansson et al. 2000a). Other lines of research have associated the presence of $A$. actinomycetemcomitans with concentrations of cytokines. Aggregatibacter (Actinobacillus) actinomycetemcomitans is a facultative anaerobic Gram-negative bacterium associated with aggressive periodontitis (Slots and Ting 1999). A. Actinomycetemcomitans possesses several different well-studied virulence factors, among which the leukotoxin us suggested to play an important role in the pathogenicity (Feng \& Weinberg). Leukotoxin is assumed to contribute to the severity of the periodontal disease by disrupting the local defense mechanisms (Guthmiller et al. 2001). Macrophages are one of the cell types involved in the local immune response and various homeostatic, immunological and inflammatory processes and contribute to specific immunity via antigen presentation and release of IL-1; they are the main source of IL-1 in inflamed tissues (Dinarello 1996). Recently a study showed that purified leukotoxin from A. actinomycetemcomitans activates caspase- 1 in human monocytes/macrophages in vitro and consequently leads to secretion of bioactive IL-1 $\beta$ (Kelk et al. 2005). Recently, a study showed that enhanced concentration IL-1 $\beta$ correlated with a high proportion of $A$. actinomycetemcomitans in samples from diseased sites of a localized aggressive periodontitis patient infected with a minimally leukotoxic strain of $A$. actinomycetemcomitans. This leukotoxin is the main cause of IL-1 $\beta$ secretion from human macrophages exposed to highly as well as minimally leukotoxic strains of $A$. actinomycetemcomitans, may indicate that leukotoxin has the potential to trigger the inflammatory response (Kelk et al. 2007). In a site of inflammation, monocytes are recruited from the peripheral circulation and need to pass through the blood vessel wall to enter the infected tissues. During this migration and later in the tissue they differentiate into macrophages and are primed by inflammatory components from the host (Perregaux et al. 2002) and microbial components from the infection (Loesche 1993). If the macrophages are exposed to a secondary factor (leukotoxin) that activates caspase-1, the level of IL1 $\beta$ secretion from these primed macrophages can be substantial and devastating for the tissue (Kelk et al. 2007).

\section{Immune response}

The transition process from gingival health to early inflammatory changes is characterized by a local increase in vascular permeability, redness, swelling and by the recruitment and activation of polymorphonuclear nutrophils (PMNs) (Delina \& Van Dyke 2000). In the course of this acute phase, several products modulate vasodilatation (e.g. bradykinin and prostaglandins), vascular permeability (e.g. histamine and leukotriene) and additional recruitment of inflammatory cells through chemotaxis (e.g. complements products and chemokines) (Offenbacher 1996). The subsequent immune response starts 
when antigen-presenting cells become involved, presenting the foreign microorganisms or antigens to immunocompetent cells such as T lymphocytes. This leads to the expansion of antibody-secreting plasma cells and the development of a chronic lesion (Gemmel \& Seymour 1994).

Based on clinical and immunological findings, the immune response in the stable gingivitis lesion is dependent on proinflammatory reactivity in progressive periodontitis lesion. For inflammatory mediators, IL-1 $\beta$, interferon (IFN)- $\gamma$ and receptor activator of nuclear factor

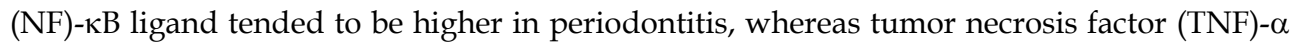
and IL-12 p40 showed no difference (Honda et al. 2006). These findings suggest that perhaps subtle differences in the balance of cytokines may result in different disease expression.

Anti-microbial peptides produced from mucosal epithelium appear to play pivotal roles in the host innate immune defense system in the oral cavity. In particular, human betadefensins (hBDs) a cathelicidin-type antimicrobial peptide, LL-37, were reported to kill periodontal disease-associated bacteria (Bals 2000). Recent studies using immunohistochemistry have demonstrated the expression of hBD-1 and hBD-2 in the gingival epithelium (Dale 2002). A variety of bacterial components are reported to induce hBD-2 mRNA expression by primary gingival epithelial cell (GEC) cultures (Weinberg et al. 1998). Recently data revealed that neutrophils expressed only LL-37, but not hBD-2 or hBD3 , and that such expression was prominent in the inflammatory lesions when compared to healthy gingival which showed very few or no LL-37 expressing neutrophils. GEC, however, expressed al three examined anti-microbial peptides, irrespective of the presence or absence of inflammation. Moreover, as determined by ELISA, the concentration of LL-37 in the gingival tissue homogenates correlated positively with the depth of the gingival crevice (Hosokawa et al. 2006).

\subsection{Polymorphonuclear neutrophils}

PMN play an important role in protection of host against invading bacteria during gingivitis. In fact, histopathology features of the gingivitis lesions show that PMN are prominent within the gingival tissues. Abundant neutrophils have been found within the connective tissue, junctional epithelium, and gingival crevice (Schroeder 1970; Attström 1971). On the other hand, absence or severe impairment of their functions results in an increased susceptibility to bacterial infection and some patients with severe peripheral blood PMN defects suffer from unusual gingivitis and destructive periodontal diseases (Ryder 2010).

PMN perform a complex series of functions during inflammatory response against bacteria: (1) adherence, required for subsequent functions performed by PMN at the inflammatory site, (2) directed migration towards chemotactic gradients, to reach the inflammatory site, (3) expression of receptors for both $\mathrm{IgG}$ and $\mathrm{C} 3 \mathrm{~b}$ on the cell surface, for the ingestion of opsonized bacteria, (4) phagocytosis, which is necessary for the clearance of pathogens, (5) release of the contents of specific granules, which is important in the regulation of themselves and other immune cells, and (5) production of antimicrobial substances.

Delivery of antimicrobial substances by PMNN is essential to control the bacterial targets and it is performed using different mechanisms: (1) Synthesis of oxygen metabolites: When PMNN contact certain stimuli (such as opsonized bacteria or chemoattractants) consume 
dioxygen through a process called respiratory burst and, by transferring 1 or 2 electrons from cytosolic NADPH to the extracellular dioxygen via the NADPH oxidase system, form toxic superoxide anion $\left(\mathrm{O}_{2}-\right)$ and hydrogen peroxide $\left(\mathrm{H}_{2} \mathrm{O}_{2}\right)$, respectively (Shapira et al. 1991; Ryder 2010). (2) Discharge of lysosomes and secretion: Antimicrobial product secretion by movilization of cytoplasmic granules called lysosomes, fusion between the lysosomes and phagosomal or plasma membrane, and discharge of granule contents into the phagosome or the external environment. (3) Phagocytosis: Implied the engulfment of particles or bacteria and their components within a phagosome. Fusion between lysosomes and phagosome form the phagolysosome, which bacteria destruction by delivered antibacterial substances at a very high concentration by intraphagolysosomal secretion and respiratory burst activity. (4) Death: Cytosolic and granule component can be delivered by apoptotic or cytolytic mechanisms.

\subsection{Cytokines}

The immune system is alerted to the presence of a pathogen through the activation of the innate immune system. The message is transmitted to the cells of the adaptive immunity through activated antigen-presenting cells. The development of specific immunity capable of eliminating the pathogen is orchestrated by cytokines and chemokines produced by the innate system. Cytokines mediate a variety of biological functions, and the network in which they act is essential (Bendtzen 1994). They act in the initiation of the effectors phase and regulate the length and extent of the response. Initially, cytokines were believed to be produced exclusively by CD4 T cells (Abbas et al. 1996), but now is clear that the arrangements of cytokines produced by cells is a result of their function and not of their phenotype (O'Garra 1998). Furthermore, cytokine production is related to the cells differentiation stage and to transitory phases of their response ( $\mathrm{O}^{\prime}$ Garra 1998). Considerable effort has been made to study the cytokine released by different host cells when exposed to components of periodontopathogenic bacteria (Offenbacher 1996). These studies have demonstrated that a number of pro-inflammatory cytokines are synthesized in response to periodontopathogenic bacteria and their products, hence inducing and maintaining an inflammatory response in the periodontium (Page 1991).

IL-1 $\beta$ is a multifunctional inflammatory mediator able to modulate bone resorption by the activation of osteoclasts (Dewhirst et al. 1985) and by stimulating prostaglandin E2 synthesis (Tatakis et al. 1988). Although this cytokine was originally considered to be a product of mononuclear phagocytes, evidence suggested that both keratinocytes and gingival fibroblasts could also produce it, in response to stimulation by bacterial products (Dinarello 1998). Data indicate that the local production of IL-1 $\beta$, in the gingival crevicular fluid, increases with increasing inflammation (Orozco et al. 2006). The levels of IL-1 $\beta$ are increased significantly in sites belonging to the adults periodontitis and early onset periodontitis (EOP) patients, compared to those belonging to the healthy and gingivitis groups (Giannopoulou et al. 2003; Girolomoni et al. 2002). Marked differences of IL-1 $\beta$ were observed in the different disease categories groups, as compared to the healthy group; a 3fold increase was noticed in the gingivitis patients, a 6-fold increase in the adults periodontitis patients and an almost 9-fold increase in the EOP group. The IL- 1 family consists of two proteins with similar biologic activities, IL- $1 \alpha$ and IL-1 $\beta$, as well as the IL-1 receptor antagonist (IL-1Ra), a non-signaling ligand. These ligands bind of two distinct and 
separate receptors, the IL-1 receptor type I (IL-RI) and IL-1RII, respectively, which are expressed on a variety of cells and the binding of IL-1 $\alpha$ and IL-1 $\beta$ to IL-1RI leads to cellular signaling and biologic effects but the binding of IL- $1 \alpha$ and IL-1 $\beta$ to IL-1RII does not lead to cellular signaling (Dinarello 1998).

IL-6 is a pleiotropic cytokine that stimulates immunoglobulin secretion by human Blymphocytes, activates T cells, stimulates the synthesis and secretion of acute phase proteins by hepatocytes, and activates the complement cascade (Revel 1999). The results showed that IL-6 is augmented in adult's periodontitis and EOP when is compared with to the healthy and gingivitis groups; the levels IL- 6 in the healthy and gingivitis groups was extremely low, but showed a 2-fold and 7-fold increase in the adult and EOP groups (Giannopoulou et al. 2003).

\subsection{T and B cells}

Studies in chronic periodontitis using and immunofluorescence support the concept that $\mathrm{T}$ lymphocytes dominate the cellular infiltrate in healthy/gingivitis lesions, while periodontitis lesions are associated with high numbers of B cells in the inflammatory infiltrate (Seymour \& Greenspan 1979; Berglund et al. 2002). Several studies revealed no statistically significant difference between the aggressive periodontitis or early onset periodontitis and chronic or adults periodontitis groups and healthy controls with regard to the relative counts of B-cells, T-cells, T-helper, T-cytotoxic/suppressor, activated T-cells and NK cells (Budunelli et al. 2001; Emingil et al. 2001; Takahashi et al. 1995). In aggressive periodontitis, existed a low number of $\mathrm{T}$ cells (CD3+) compared to healthy/gingivitis biopsies and this reduction of CD3+ could indicate that other lymphocytic cells like B lymphocytes may play an important role in the immune response that mediates damage in aggressive periodontitis (Suarez et al. 2004).

$\mathrm{T}$ cells are present in the inflammatory infiltrates of periodontal disease lesions and require antigen presentation by antigen-presenting cells (APCs). The presence of numerous CD1a+ Langerhans cells was noted in the epithelium with no difference between the healthy/gingivitis and periodontitis group (Gemmell et al. 2003). Five times as many CD1a+ Langerhans cells have been shown in clinically inflamed gingival epithelium compared with numbers in the same patients following periodontal treatment (DiFranco 1985).

While T cells exhibit immunoregulatory features via T-helper 1 and T-helper 2 subsets, B cells upon activation transform into antibody producing plasma cells. Polyclonal B-cell activation is believed to be of major significance in the development of B-cell lesions (Tew et al. 1989). Yamazaki et al. showed that the frequency of B-cells and activated B-cells in the periodontitis was much higher than that of gingivitis lesions, suggest that the periodontal lesions is also dominated by B cells in the tissue (Yamazaki et al. 1993,28). This was substantiated by the results of Afar et al., who demonstrated a marked increase in a B-cell subpopulation -namely the autoantibody-producing CD20+ CD5+ cells- of patients with periodontitis (Afar et al. 1992). The results of CD40L expression, in the gingival tissue of periodontitis patients, suggest that , CD40L-expressing activated T cells stimulate B cells by cross-linking CD40 molecules to proliferate and differentiate to plasma cells and subsequent immunoglobulin production (Orima et al. 1999).

\subsection{Matrix metalloproteinases (MMPs) in gingivitis}

Extracellular proteolysis and remodeling of the extracellular matrix from periodontal tissues is an integral feature of periodontal homeostasis involving a tight balance among protease 
activities and inhibition. Matrix metalloproteinase's (MMPs) are genetically distinct but structurally related zinc-dependent metalloendopeptidases, described almost fifty years ago (Gross and Lapiere, 1962). MMPs can synergistically degrade almost all extracellular matrix and basement membrane components and regulate several cellular processes including inflammatory responses, representing the most prominent and widely studied family of proteinases associated with periodontal diseases (Folgueras et al., 2004; Overall, 2002; Sorsa et al., 2006).

Type I collagen is the major extracellular matrix component of connective periodontal tissues setting collagenolytic MMPs among the most prominent mediators and biomarker candidates for periodontal tissue breakdown (Golub et al., 1997; Kiili et al., 2002; Rodan and Martin, 2000). Since their discovery, collagenolytic MMPs were promptly identified in gingival (Geiger and Harper, 1980; Gibson and Fullmer, 1966) and gingival crevicular fluid (GCF) (Golub et al., 1976) in association with the degree of gingival inflammation (Overall and Sodek, 1987). So far, a burst of evidence supports that collagenases along with other MMPs play a pivotal role in periodontal tissue destruction (Sorsa et al., 2006).

The major collagenolytic MMPs associated with severity of periodontal inflammation and disease are MMP-8 and MMP-13. MMP-2 and MMP-9 belong to the gelatinase family of MMPs that further degrade denatured collagen basement membranes, among other substrates. Whereas MMP-2 expression is constitutive, MMP-9 is strongly induced during inflammatory conditions (Kiili et al., 2002; Sorsa et al., 1988; Sorsa et al., 2006; Tervahartiala et al., 2000; Uitto et al., 2003).

MMP-8 and MMP-9 are by far the predominant MMPs in GCF and their major source are regarded to be neutrophils, monocytes and macrophages, although resident periodontal cells can also produce these MMPs. MMP-9 has also been detected in junctional sulcular and pocket gingival epithelial cells and thus it might be involved in epithelial response during periodontitis (Smith et al., 2004). Increasing of MMP-8 and MMP-9 are substantially involved in chronic periodontitis (Hernandez et al., 2010; Hernandez Rios et al., 2009; Pozo et al., 2005) and represent the most promising biomarkers for periodontal inflammation and disease severity (Sorsa et al., 2009). Active forms of MMP-8 tend to increase during disease progression, whereas neutrophil MMP-8 is the predominant isotype. Nevertheless, physiological MMP-8 levels might be required for normal tissue turnover and are thought to be rather protective against periodontal destruction (Hernandez et al., 2011; Kuula et al., 2009).

MMP-13 on the other hand, is much less abundant in GCF. MMP-13 is expressed by sulcular epithelial cells, macrophage-like cells, fibroblasts, plasma cells and osteoblasts (Hernandez et al., 2006; Rydziel et al., 2000). MMP-13 levels are shown to increase in chronic periodontitis in comparison to healthy periodontium, whereas MMP-13 increased activity has mainly been related to the occurrence of the loss of periodontal supporting tissue and alveolar bone resorption. Additionally, MMP-13 can activate proMMP-9 in diseased gingival tissue (Hernandez Rios et al., 2009).

Although a strong body of evidence supports that MMP-8, MMP-9 and MMP-13 play an important role in periodontal inflammation and/or supporting tissue loss, few studies have focused on the role of these proteinases in gingivitis and reports are somewhat conflicting. Previous determinations of MMP -1, -2, -9 and -13 expression through real time-PCR showed no differences among gingival samples from healthy, gingivitis and periodontitis 
subjects, but a tendency for both gelatinases to increase in inflamed tissues (Goncalves et al., 2008). Conversely, MMP-8 and MMP-9 protein levels, as well as total collagenase activity have been found to increase progressively from healthy periodontal tissues and gingivitis to periodontitis in GCF and/or saliva samples (Mantyla et al., 2003; Rai et al., 2008; Xu et al., 2008). Nonetheless, a recent study reported significant increases in GCF IL -1 $\beta$ levels along with an overall decrease of MMPs in experimental gingivitis model, except for MMP-8. The authors also described different subsets of inflammatory phenotypes based on cluster analysis of changes in GCF mediators that resulted in a similar clinical phenotype. One of the inflammatory phenotypes appeared to be similar to periodontitis, consisting of increases in IL-1 $\alpha$ and IL-1 $\beta$, IL-6, MMP-8 and MMP-9, along with a significant decrease in macrophage inflammatory protein (MIP)-1 $\beta$. This finding suggests that host response during gingivitis might be heterogeneous and some of the inflammatory phenotypes could be more susceptible to periodontitits development (Offenbacher et al., 2010). Accordingly, elevation of active MMP-8 has previously been associated with the conversion of gingivitis to periodontitis and established periodontitis (Mantyla et al., 2006).

Despite MMP-13 has been more related to chronic periodontitis progression than severity of inflammation, it has previously been reported that MMP-13 also increase progressively from healthy subjects to periodontitis in GCF. Higher levels of active forms and total MMP-13 have been described in gingivitis versus healthy sites; whereas MMP-13 levels and active forms were significantly higher in chronic periodontitis, compared to both, healthy and gingivitis subjects (Ilgenli et al., 2006). Furthermore, chronic periodontitis subjects show higher MMP-13 activity in active sites compared to inactive sites and healthy controls.

\section{Acknowledgment}

This study was supported by project grants 1090046 and 1090461 from Scientific and Technologic Investigation Resource (FONDECYT), Santiago, Chile. The authors declare that they have no conflict of interests

\section{References}

Abbas AK, Murphy KM, Sherr A. Functional diversity of helper T lymphocytes. Nature 1996,383:787-793

Armitage GC. Development of a classification system for periodontal disease and conditions. Ann Periodontol 1999,4:1-6.

Asai Y, Ohyama Y, Gen K, OgawaT. Bacterial fimbriae and their peptide activate human gingival epithelial cells through Toll-like receptor 2. Infect Immun 2001 69:73877395

Attström R. Studies on neutrophil polymorphonuclear leukocytes at the dento-gingival junction in gingival health and disease. J Periodont Res 1971; Suppl 8:1-15.

Bals R. Epithelial anti-microbial peptides in host defense against infection. Respir Res 2000,1:141-150

Bendtzen K. Cytokine and natural regulators of cytokine. Immunol Lett 1994,43:111-123

Berglund T, Liljenberg B, Lindhe J. Some cytokine profiles of T-helper cells in lesions of advanced periodontitis. J Clin Periodontol 2002:29:705-709 
Chapple, C.C., Srivastava, M. \& Hunter, N. Failure of macrophage activation in destructive periodontal disease. J Pathol 1998, 186:281-286.

Budunelli N, Bicakci N, Keskinoglu A. Flow-citometryc analysis of lymphocyte subsets and mCD14 expression in patients with various periodontitis categories. J Clin Periodontol 2001,28:419-424

Dale BA. Periodontal epithelium: a newly recognized role in health and disease. Periodontology 2000,2002,30:70-78

Darveau RP, Belton CM, Reife RA, Lamont RJ. Local chemokine paralysis, a novel pathogenic mechanims for P. gingivalis. Infect Immun 1998,66:1660-1665

Delina AJ, Van Dyke TE. Origin and function of the cellular components in gingival crevice fluid. Periodontology 2000,31:55-76

Dewhirst FE, Stashenko PP, Mole JE, Tsurumachi T. Purification and partial sequence of human osteoclast-activating factor. Identity with interleukin $1 \beta$. J Immunol 1985,135:2562-1566

DiFranco CF, Toto PD, Rowden G, Gargiulo AW, Keene JJ Jr, Connelly E. Identification of Langerhans cells in human gingival epithelium. J Periodontol 1985,56:48-54

Dinarello CA. Interleukin-1, interleukin-1 receptors and interleukin-1 receptor antagonist. Int Rev Immunol 1998,16:457-499

Dongari-Bagtzoglou AI, Ebersole JL. Production of inflammatory mediators and cytokines by human gingival fibroblasts following bacterial challenge. J Periodon Res 1996,31:90-98

Emingil G, Karaarslan F, Keskinoglu A, Coker I, Atilla G. Phenotypic and functional analysis of peripheral blood mononuclear cells in generalized aggressive and chronic periodontitis patients. J Int Acad Periodontol 2001,3:87-94

Feng Z, Weinberg A. Role of bacteria in health and disease of periodontal tissues. Periodontol 2000 2006,40:50-76

Finlay BB, McFadden GM. Anti-immunology: evasion of the host immune system by bacterial and viral pathogens. Cell 2006,124:767-782

Folgueras AR, Pendas AM, Sanchez LM, Lopez-Otin C (2004). Matrix metalloproteinases in cancer: from new functions to improved inhibition strategies. Int J Dev Biol 48(56):411-24.

Gemmel E, Seymour GJ. Modulation of immune resposes to periodontal bacteria. Curr Opin Periodontol 1994,28-38

Gemmell E, Carter CL, Hart D, Drysdale K, Seymour GJ. Antigen-presenting cells in human periodontal disease tissues. Oral Microbiology Immunology 2003,18:388-393

Gemmell, E. et al. Costimulatory molecules in human periodontal disease tissues. Journal of periodontal research, 2001, 36:92-100.

Gemmell, E. et al. Antigen-presenting cells in human periodontal disease tissues. Oral microbiology and immunology 2002, 17: 388-393.

Geiger S, Harper E (1980). Human gingival collagenase in periodontal disease: the release of collagenase and the breakdown of endogenous collagen in gingival explants. J Dent Res 59(1):11-6.

Gibson W, Fullmer H (1966). Collagenolytic activity of gingival tissues in vitro. J Dent Res 45(4):1225. 
Golub LM, Siegel K, Ramamurthy NS, Mandel ID (1976). Some characteristics of collagenase activity in gingival crevicular fluid and its relationship to gingival diseases in humans. J Dent Res 55(6):1049-57.

Goncalves LD, Oliveira G, Hurtado PA, Feitosa A, Takiya CM, Granjeiro JM, et al. (2008). Expression of metalloproteinases and their tissue inhibitors in inflamed gingival biopsies. J Periodontal Res 43(5):570-7.

Gross J, Lapiere CM (1962). Collagenolytic activity in amphibian tissues: a tissue culture assay. Proc Natl Acad Sci US A 48(1014-22.

Giannopouu C, Kamma JJ, Mombelli A. Effect of inflammation, smoking an stress on gingival crevicular fluid cytokine level. J Clin Periodontol 2003;30:145-153

Grossi SG, Zambon JJ, Ho AW, et al. Assessment of risk for periodontal disease. I. Risk indicators for attachment loss. J Periodontol 1994,65:260-267.

Guthmiller JM, Lally ET, Korostoff J. Beyond the specific plaque hypothesis: are highly leukotoxic strains of Actinobacillus actinomycetemcomitans a paradigm for periodontal pathogenesis? Crit Rev Oral Biol Med 2001,12:116-124

Haffaje AD, Socransky SS. Microbial etiological agents of destructive periodontal diseases. Periodontology 2000 1994,5:78-111

Hajishengallis G, Wang M, Harokopakis E, Triantafilou M, Triantafilou K. Porphyromonas gingivalis fimbriae proactively modulate $\beta 2$ integrin adhesive activity and promoting binding to and internalisation by macrophages. Infect Immun 2006,74:5658-5666

Hernandez M, Valenzuela MA, Lopez-Otin C, Alvarez J, Lopez JM, Vernal R, et al. (2006). Matrix metalloproteinase-13 is highly expressed in destructive periodontal disease activity. J Periodontol 77(11):1863-70.

Hernandez M, Gamonal J, Tervahartiala T, Mantyla P, Rivera O, Dezerega A, et al. (2010). Associations between matrix metalloproteinase- 8 and -14 and myeloperoxidase in gingival crevicular fluid from subjects with progressive chronic periodontitis: a longitudinal study. J Periodontol 81(11):1644-52.

Hernandez M, Gamonal J, Salo T, Tervahartiala T, Hukkanen M, Tjaderhane L, et al. (2011). Reduced expression of lipopolysaccharide-induced CXC chemokine in Porphyromonas gingivalis-induced experimental periodontitis in matrix metalloproteinase-8 null mice. J Periodontal Res.

Hernandez Rios M, Sorsa T, Obregon F, Tervahartiala T, Valenzuela MA, Pozo P, et al. (2009). Proteolytic roles of matrix metalloproteinase (MMP)-13 during progression of chronic periodontitis: initial evidence for MMP-13/MMP-9 activation cascade. J Clin Periodontol 36(12):1011-7.

Hoebe BB, Ulevitch RJ. Wow we detect microbes and respond to them: the Toll-like receptors and their transducers. J Leukoc Biol 2003,74:479-485

Honda T, Domon H, Okui T, Kajita K, Amanuma R, Yamazaki K. Balance of inflammatory response in stable gingivitis and progressive periodontitis lesions. Clinical and experimental immunology. 2006,144:35-40

Hosokawa I, Hosokawa Y, Komatsuzawa H, et al. Innate immune peptide LL-37 displays distinct expression pattern from beta-defensins in inflamed gingival tissue. Clinical and Experimental Immunology 2006,146:218-225 
Ilgenli T, Vardar-Sengul S, Gurkan A, Sorsa T, Stackelberg S, Kose T, et al. (2006). Gingival crevicular fluid matrix metalloproteinase-13 levels and molecular forms in various types of periodontal diseases. Oral Dis 12(6):573-9.

Ji S, Kim Y, Min BM, Han SH, Choi Y. Innate immune responses of gingival epithelial cells to nonperiodontopathic and periodontopathic bacteria. J Periodont Res 2007,42:503510

Johansson A, Sandstrom G, Claesson R, Hanstrom L, Kalfas S. Anaerobic neutrophildependent killing of Actinobacillus actinomycetemcomitans in relation to the bacterial leukotoxicity. Eur J Oral Aci 2000a 108:136-146

Kelk P, Claesson R, Hanstrom L, Lerner UH, Kalfas S, Johansson A. Abundant secretion of bioactive interleukin-1beta by human macrophages induced by Actinobacillus actinomycetemcomitans leukotoxin. Infect Immun 2005,73:453-458

Kiili M, Cox SW, Chen HY, Wahlgren J, Maisi P, Eley BM, et al. (2002). Collagenase-2 (MMP8) and collagenase-3 (MMP-13) in adult periodontitis: molecular forms and levels in gingival crevicular fluid and immunolocalisation in gingival tissue. J Clin Periodontol 29(3):224-32.

Kuula H, Salo T, Pirila E, Tuomainen AM, Jauhiainen M, Uitto VJ, et al. (2009). Local and systemic responses in matrix metalloproteinase 8-deficient mice during Porphyromonas gingivalis-induced periodontitis. Infect Immun 77(2):850-9.

Lamont RJ, Jenkinson HF. Life below the gum line: pathogenic mechanisms of Porphyromonas gingivalis. Microbiol Mol Biol Rev 1998,62:1244-1263

Mantyla P, Stenman M, Kinane DF, Tikanoja S, Luoto H, Salo T, et al. (2003). Gingival crevicular fluid collagenase-2 (MMP-8) test stick for chair-side monitoring of periodontitis. J Periodontal Res 38(4):436-9.

Mantyla P, Stenman M, Kinane D, Salo T, Suomalainen K, Tikanoja S, et al. (2006). Monitoring periodontal disease status in smokers and nonsmokers using a gingival crevicular fluid matrix metalloproteinase-8-specific chair-side test. J Periodontal Res 41(6):503-12.

Milward MR, Chapple IL, Wright HJ, Millard JL, Matthews JB and Cooper PR. Differential activation of NF- $\mathrm{KB}$ and gene expression in oral epithelial cells by periodontal pathogens. Clin Exper Immunol 2007:148:307-324

O'Garra A. Cytokines induced the development of functionally heterogeneous $\mathrm{T}$ helper cell subsets. Immunity 1998;8:275-283

Offenbacher, S. Peridontal diseases: pathogenesis. Annals of Periodontology 1996,1,821878

Offenbacher, S et al., Periodontal disease at the biofilm-gingival interface. J Periodontol/Annals of periodontology / AAP, 2007, 78:1911-1925.

Offenbacher, Steven et al., Changes in gingival crevicular fluid inflammatory mediator levels during the induction and resolution of experimental gingivitis in humans. Journal of Clinical Periodontology 2010, 37:324-333.

Offenbacher S, Barros S, Mendoza L, Mauriello S, Preisser J, Moss K, et al. (2010). Changes in gingival crevicular fluid inflammatory mediator levels during the induction and resolution of experimental gingivitis in humans. J Clin Periodontol 37(4):324-33. 
Ogawa T. Immunobiological properties of chemically defined lipid A from lipopolysaccharide of Porphyromonas (Bacteroides) gingivalis Eur J Biochem 1994,219:737-742

Orima K, Yamazaki K, Aoyagi T, Hara K. Differential expression of costimulatory molecules in chronic inflammatory periodontal disease tissue. Clin Exp Immunol 1999,115:153-160

Orozco A, Gemmell E, Bickel M, Seymour GJ. Interleukin-1 $\beta$, interleukin-12 and interleukin18 levels in gingival fluid and serum of patients with gingivitis and periodontitis. Oral Microbiol Immunol 2006,21:256-260

Overall CM, Sodek J (1987). Initial characterization of a neutral metalloproteinase, active on native 3/4-collagen fragments, synthesized by ROS 17/2.8 osteoblastic cells, periodontal fibroblasts, and identified in gingival crevicular fluid. J Dent Res 66(7):1271-82.

Overall CM (2002). Molecular determinants of metalloproteinase substrate specificity: matrix metalloproteinase substrate binding domains, modules, and exosites. Mol Biotechnol 22(1):51-86.

Page RC, Schroeder HE. Pathogenesis of chronic inflammatory periodontal disease: A summary of current work. Lab Invest 1976:33:235-249

Page RC. The rol of inflammatory mediators in the pathogenesis of periodontal disease. J Periodont Res 1991,26:230-242

Perregaux DG, Bhavsar K, Contillo L, Shi J, Gabel CA. Antimicrobial peptides initiate IL-1 bets posttranslational processing: a novel role beyond innate immunity. J Immunol 2002,168:3024-3032

Pozo P, Valenzuela MA, Melej C, Zaldivar M, Puente J, Martinez B, et al. (2005). Longitudinal analysis of metalloproteinases, tissue inhibitors of metalloproteinases and clinical parameters in gingival crevicular fluid from periodontitis-affected patients. J Periodontal Res 40(3):199-207.

Revel M. Host defense against infections and inflammations: Role of the multifunctional IL6/IFN- $\beta 2$ cytokine. Experentia 1999,45:549-557

Ryder MI. Comparison of neutrophil functions in aggressive and chronic periodontitis. Periodontol 2000 2010;53:124-137

Rai B, Kharb S, Jain R, Anand SC (2008). Biomarkers of periodontitis in oral fluids. J Oral Sci 50(1):53-6.

Rodan GA, Martin TJ (2000). Therapeutic approaches to bone diseases. Science 289(5484):1508-14.

Rydziel S, Durant D, Canalis E (2000). Platelet-derived growth factor induces collagenase 3 transcription in osteoblasts through the activator protein 1 complex. J Cell Physiol 184(3):326-33.

Sawada N, Ogawa T, Asai Y, Makimura Y, Sugiyama A. Toll-like receptor 4-dependent recognition of structurally different forms of chemically synthesized lipid as of Porphyromonas gingivalis. Clin Exp Immunol 2007,148:529-536

Scheres N, Laine ML, de Vries TJ, Everts V, van Winkelhoff. Gingival and periodontal ligament fibroblasts response to viable Porphyromonas gingivalis. J Periodont Res 2010,45:262-270

Schroeder HE. The structure and relationship of plaque to the hard and soft tissues: Electron microscopic interpretation. Int Dent J 1970;20:353-381 
Seymour GJ, Greenspan JS. The phenotypic characterization of lymphocyte subpopulations in established human periodontal disease. J Periodontal Res 1979:14:39-46

Seymour GJ. Possible mechanisms involved in the immunoregulation of chronic inflammatory periodontal disease. J Dent Res 1987,66:2-9

Shapira L, Borinski R, Sela MN, Soskolne A. Superoxide formation and chemiluminescence of peripheral polymorphonuclear leukocytes in rapidly progressive periodontitis patient. J Clin Periodontol 1991;18:44-48

Slots J, Listgarten MA. Bacteroides gingivalis, Bacteroides intermedius and Actinobacillus actinomycetemcomitans in human periodontal diseases. J Clin Periodontol 1988,1585-93

Suarez LJ, Ocampo AM, Duenas RE, Rodriguez A. Relative proportions of T-cell subpopulations and cytokines that mediate and regulate the adaptive imnune response in patients with aggressive periodontitis. J Periodontol 2004:75:12091215

Sugawara Y, Uehara A, Fujimoto Y et al. Toll-like receptors, NOD1 and NOD2, in oral epithelials cells. J Dent Res 2006 85:524-529

Smith PC, Munoz VC, Collados L, Oyarzun AD (2004). In situ detection of matrix metalloproteinase-9 (MMP-9) in gingival epithelium in human periodontal disease. J Periodontal Res 39(2):87-92.

Sorsa T, Uitto VJ, Suomalainen K, Vauhkonen M, Lindy S (1988). Comparison of interstitial collagenases from human gingiva, sulcular fluid and polymorphonuclear leukocytes. J Periodontal Res 23(6):386-93.

Sorsa T, Tjaderhane L, Konttinen YT, Lauhio A, Salo T, Lee HM, et al. (2006). Matrix metalloproteinases: contribution to pathogenesis, diagnosis and treatment of periodontal inflammation. Ann Med 38(5):306-21.

Sorsa T, Hernandez M, Leppilahti J, Munjal S, Netuschil L, Mantyla P (2009). Detection of gingival crevicular fluid MMP-8 levels with different laboratory and chair-side methods. Oral Dis 16(1):39-45.

Takahashi K, Nagai A, Satoh N, Kurihhara H, Muruyama Y. Studies on the phenotypic and functional characterization of peripheral blood lymphocytes from patients with early-onset periodontitis. J Periodontol 1995,66:391-396

Tatakis DN, Schneeberger G, Dziak R. Recombinant interleukin 1 stimulates prostaglandin E2 production by osteoblastic cells. Synergy with parathyroid hormone. Calc Tissues Int 1988,42:358-362

Tew J, Engel D, Mangan D. Polyclonal B cell activation in periodontitis. J Periodont Res 1989,24:225-241

Tervahartiala T, Pirila E, Ceponis A, Maisi P, Salo T, Tuter G, et al. (2000). The in vivo expression of the collagenolytic matrix metalloproteinases (MMP-2, -8, -13, and -14) and matrilysin (MMP-7) in adult and localized juvenile periodontitis. J Dent Res 79(12):1969-77.

Uehara A, Takada H. Functional TLRs and NODs in human gingival fibroblats. J Dent Res 2007 86,249-254

Uitto VJ, Overall CM, McCulloch C (2003). Proteolytic host cell enzymes in gingival crevice fluid. Periodontol 2000 31(77-104. 
Wang M, Shakhatreh M, James D et al. Fimbrial proteins of Porphyromonas gingivalis mediate in vivo virulence and exploit TLR2 and complement receptor 3 to persist in macrophages. J Immunol 2007,179:2349-2358

Weinberg A, Krisanaprakornkit S, Dale BA. Epithelial anti-microbial peptides: review and significance for oral applications. Crit Rev Oral Biol Med 1998,9:399-414

Xu L, Yu Z, Lee HM, Wolff MS, Golub LM, Sorsa T, et al. (2008). Characteristics of collagenase-2 from gingival crevicular fluid and peri-implant sulcular fluid in periodontitis and peri-implantitis patients: pilot study. Acta Odontol Scand 66(4):219-24.

Yamazaki K, Nakajima T, Aoyagi T, Hara K. Immunohistological analysis of memory T lymphocytes and activated B lymphocytes in tissues with periodontal disease. J Periodont Res 1993,28:324-334 


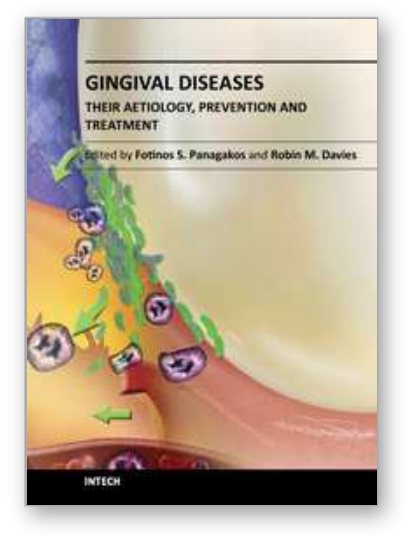

\author{
Gingival Diseases - Their Aetiology, Prevention and Treatment \\ Edited by Dr. Fotinos Panagakos
}

ISBN 978-953-307-376-7

Hard cover, 230 pages

Publisher InTech

Published online 22, September, 2011

Published in print edition September, 2011

Gingival diseases are a family of distinct pathological entities that involve the gingival tissues. These signs and symptoms of these diseases are so prevalent in populations around the world that they are often considered to be â€œnormalâ€ features. The diseases are now classified into two main groups namely: Plaque-Induced and Non-Plaque Induced Gingival Diseases. This book provides dentists, dental hygienists, dental therapists and students with a comprehensive review of gingival diseases, their aetiology and treatment.

\title{
How to reference
}

In order to correctly reference this scholarly work, feel free to copy and paste the following:

Jorge Gamonal, Nora Silva, Marcela Hernández, Nicolás Dutzan, Jocelyn Garcia-Sesnich, Loreto Abusleme, Andrea Dezerega and Rolando Vernal (2011). Components of Host Response to Pathogenic Bacteria in Gingivitis, Gingival Diseases - Their Aetiology, Prevention and Treatment, Dr. Fotinos Panagakos (Ed.), ISBN: 978-953-307-376-7, InTech, Available from: http://www.intechopen.com/books/gingival-diseases-theiraetiology-prevention-and-treatment/components-of-host-response-to-pathogenic-bacteria-in-gingivitis

\section{INTECH}

open science | open minds

\author{
InTech Europe \\ University Campus STeP Ri \\ Slavka Krautzeka 83/A \\ 51000 Rijeka, Croatia \\ Phone: +385 (51) 770447 \\ Fax: +385 (51) 686166 \\ www.intechopen.com
}

\author{
InTech China \\ Unit 405, Office Block, Hotel Equatorial Shanghai \\ No.65, Yan An Road (West), Shanghai, 200040, China \\ 中国上海市延安西路65号上海国际贵都大饭店办公楼 405 单元 \\ Phone: +86-21-62489820 \\ Fax: $+86-21-62489821$
}


(C) 2011 The Author(s). Licensee IntechOpen. This chapter is distributed under the terms of the Creative Commons Attribution-NonCommercialShareAlike-3.0 License, which permits use, distribution and reproduction for non-commercial purposes, provided the original is properly cited and derivative works building on this content are distributed under the same license. 